\title{
Dynamic Geometry Software: The Teacher's Role in Facilitating Instrumental Genesis
}

Nicola Bretscher

King's College London

In the UK, teachers' use of dynamic geometry software (DGS) has remained limited. The importance of the teacher's role is often stated in dynamic geometry research but has been seldom elaborated. This study aims to address the apparent deficiency in research. The author conducted the research in the role of a practitioner-researcher with a high ability year 8 class. By analysing teacher/pupil interactions in a DGS context, elements of instrumental genesis are distinguished in pupils' dialogue and written work which suggest strategies that teachers can employ to facilitate this process. Whilst these strategies are specific to a DGS context, they highlight general principles of mathematics teaching. This paper argues that the focus of research needs to shift away from the context, towards teachers and the strategies they employ.

Keywords: Teacher's role; Dynamic geometry; Instrumental genesis

\section{Introduction}

This study aims to elicit teaching strategies that teachers might employ in their classrooms to help pupils engage constructively with DGS. Currently DGS has made little impact in the UK: despite recommendations in the Key Stage 3 Mathematics Framework for using DGS to develop geometrical reasoning, classroom use has remained limited (Ofsted 2004). Research generally presents DGS as a potentially important and effective tool in the teaching and learning of geometry, however it has tended to focus on elaborating situations of innovative use and student/machine interaction. Lagrange et al (2003) paint a picture of research on ICT in mathematics education as a field dominated by "publications about innovative use or new tools and applications" where issues of the integration of technology into ordinary classrooms have been largely neglected. In particular, the voice and role of the teacher has been notably absent. This study hopes to re-focus on "the teacher dimension" (Lagrange et al. 2003). The author carried out this study in the role of a practitioner-researcher with a high ability year 8 class. Whilst the class cannot be deemed to be representative, nevertheless this study can claim to respond to the need for research into how DGS is integrated into the ordinary classroom.

The instrumental approach, described in the next section, was used to analyse teacher/pupil interactions in order to draw out teaching strategies which might facilitate pupils' instrumental genesis.

\section{The Instrumental Approach}

Instrumental genesis is described as the process by which an artefact is transformed into an instrument by the subject or user (Guin and Trouche 1999). An artefact is a 
material or abstract object, given to a subject. An instrument is a psychological construct built from the artefact by the subject internalising its constraints, resources and procedures (Guin and Trouche 1999). Once the user has achieved instrumentalisation, he is able to reinterpret or reflect on the activity he is engaged in. Drijvers and Gravemeijer (2005) describe instrumental genesis as the "emergence and evolution of utilisation schemes". A utilisation scheme is a "stable mental organisation" including both technical skills and supporting concepts as a method of using the artefact for a given class of tasks (Drijvers and Gravemeijer 2005). The interrelation between machine techniques and concepts seems important since Drijvers and Gravemeijer (2005) found that the apparent technical difficulties that students had often had a conceptual background.

The instrumental approach has been mainly developed and applied within the context of computer algebra software (Drijvers and Gravemeijer 2005) and there remains a question over how general its applicability is. Drijvers and Gravemeijer (2005) cite two examples where the instrumental approach has been applied to DGS. Thus it seems instrumental genesis may be an appropriate tool to analyse observations of student behaviour within a dynamic geometry environment.

\section{Research context and methodology}

This study was conducted as part of a Best Practice Research Scholarship-funded project on using DGS as a resource for teaching geometrical proof. The research was conducted with year 8 pupils in response to the need for more research on the impact of DGS on students in lower secondary school (Marrades and Gutiérrez 2000). An added advantage was that year 8 pupils are not subject to public examinations, the curriculum is less pressurised and therefore ethical considerations about deviating from schemes of work were somewhat reduced. The school in which the research was conducted is a private day school for girls. The research was conducted with the highest attaining set in year 8 , containing 23 pupils, with girls expected to achieve levels 7 or 8 at Key Stage 3. In common with several other research studies, this was seen as an advantage since students judged to be above average in mathematical ability are most likely to be able to engage with proving processes and therefore allow meaningful data collection to take place (Jones 2000; Marrades and Gutiérrez 2000).

In this paper, I consider data drawn from a sequence of 5 lessons in which pupils, working in pairs, investigated a series of construction problems using Cabri Geometre, based upon tasks developed by Jones (2000). Each task consisted of a figure which the pupils had to construct in Cabri so that it remained constant under drag. The pupils were prompted to say what the resultant shape was and, importantly, how did they know? The point of the teaching sequence was to encourage pupils to justify or prove these assertions. The pupils were asked to choose a construction of their choice and produce a Power-point presentation explaining their construction. Printouts of the pupils' work and audiotape recordings of their presentations to the class form one part of the data collected. During the lessons, the researcher carried an audiotape so that any teacher/pupil interactions would be recorded: these recordings form another part of the data collected. After the lessons, brief field-notes were made on the major events in the lesson.

The initial stage of data analysis concerned the transcription of taperecordings made during lessons. Using field notes, the tapes were broken down into major events or "episodes" (Bliss et al 1996). In the sense described by Bliss et al 
(1996) these episodes had "an internal coherence"; they were complete conversations which allowed the researcher to "interrupt momentarily, for the purpose of analysis, the 'relentless flow of the lesson"'. A second stage of analysis involved going through the transcripts and pupils' work making notes, identifying critical incidents that build towards detailed accounts of practices. The final analysis was based on a grounded approach using narrative techniques (Kvale 1996) which moved back and forth between the theoretical viewpoint developed in the review of literature and the pupils' work and transcribed episodes. Each step in this process eased the transition from emotionally involved participant towards objective observer.

\section{Analysis}

From the analysis of data, three teaching strategies emerged for facilitating pupils' instrumental genesis in Cabri. Using excerpts from teacher/pupil dialogue, these strategies are described below, where T represents the teacher throughout.

\section{Unravelling functional dependency in DGS}

In common with other students, Pupils $\mathrm{H}$ and $\mathrm{C}$ experienced difficulty with specifying where they wanted objects to intersect when attempting to construct two circles sharing the same radius. They constructed the first circle successfully and correctly placed the centre of the second circle on its edge. The difficulty arose when they tried to adjust the size of the second circle so that its edge would pass through the centre of the first circle, thus ensuring that they would share a radius. The problem was that they made it look like the edge of the second circle passed through the centre of the first circle rather than specifying to Cabri that the circle should go "By this point" - as the Cabri pop-up phrase suggests if you hover over the required centre point. Although their Cabri drawing looked successful, when it was subjected to a drag-test, the circles changed size in relation to each other instead of maintaining their pattern:

T: Yeahhh. That's it because you see this computer program will only do exactly what you tell it so if you just make it look like it... sort of, yeah. I'm going to be able to change the shape of your circle so if you tell it, look....

crackle: teacher using the computer to show how the circle can still be messed up. Then creates a new circle "by this point" method to show the difference

$\mathrm{T}$ :

Ok now try and mess it up, you try and mess it up now mess up one of the other circles yeah... ok so...

There follow some unintelligible comments, then...

H: You think a computer's smart but it's not, you can't just sit there and watch it do it for you, you have to know what to do and you have to tell it to do it so it's like a something.... like it's like a lightswitch.

The difficulties that students have in coming to terms with the concept of functional dependency in geometry exemplifies Drijvers and Gravemeijer's (2005) conception of utilisation schemes in which the technical and conceptual elements coevolve. Pupil $\mathrm{H}$ articulates this point very clearly: "you have to know what to do and you have to tell it to do it". Mathematical knowledge is knowing "what to do" and technical knowledge is required in order to tell the computer to do it. The gap in $\mathrm{H}$ 
and C's knowledge was an appreciation of the functional dependencies inherent in Cabri: on the one hand, a conceptual gap of the necessity of specifying the required geometrical relationship and, on the other hand, a gap in the technical knowledge of how to specify the relationship using Cabri. The teacher explains the need to specify the geometrical relationship: the "computer program will only do exactly what you tell it". The teacher illustrates the technical knowledge of how to specify the relationship by contrasting the construction 'by eye', which could still be messed-up, to the "by this point" version in which the geometrical relationships remained intact.

Drijvers and Gravemeijer (2005) describe instrumental genesis as the "emergence and evolution of utilisation schemes, in which technical and conceptual elements co-evolve". The role of the teacher in supporting instrumental genesis is partly in making the technical and conceptual elements explicit. In the case of DGS such as Cabri, the teacher's role is to unravel the notion of functional dependency by highlighting the necessity of specifying the required geometrical relationship and the technical knowledge of how to specify the relationship.

\section{Exploiting dynamic variation to highlight geometric invariance}

All the construction problems were based on the initial construction of a line which was presented to be horizontal. Of course, there is no geometrical reason for the line to be horizontal, the figures were presented in this way for neatness and it had not been given a second thought, until the teacher noticed that all students appeared to be constructing intentionally horizontal lines. The pupils had discovered that by pressing the "shift" key whilst constructing a line, the line would snap to the horizontal. Pupil $\mathrm{K}$ was insistent that the line should be horizontal:

T: $\quad$ Why do you always insist on that being horizontal? Does it matter if it....

The teacher draws attention to the pupil's misconception and, by dragging, attempts to convey that the horizontal constraint is artificial, that it can be broken without disturbing the figure under construction. As the pupils were presenting their work to the class, it became clear that all groups had produced figures with horizontal lines. The teacher again attempted to question this feature of their constructions but this time in a whole class context. Pupil MC was asked to reconstruct her solution to Problem 2 (a perpendicular bisector) without starting from a horizontal line. She did this successfully on an interactive whiteboard so that the whole class could see. She then dragged the figure, directed by the teacher, changing its orientation to show its invariance, including the situation with the initial line being horizontal. The teacher exploits dynamic variation to highlight the geometric invariance of the construction in order to help pupils differentiate between geometrical relationships which were or were not crucial.

\section{Making connections between DGS and pencil-and-paper}

Pupil $\mathrm{N}$ had constructed a rhombus but had difficulty identifying the shape due to its unfamiliar orientation. The teacher employs dynamic variation to convince pupil $\mathrm{N}$ that the shape is indeed a rhombus but then continues the explanation on paper:

$\mathrm{N}: \quad$ Is this a rhombus? But a rhombus supposed to be like tilted so...?

Teacher manipulating the diagram on screen

$\mathrm{N}$ : Oh so it can be, it can be any way up and it [T: Oh!] would still be a rhombus. 
$\mathrm{T}:$

Well yeah... [N to another pupil: Well it is a rhombus.] it's like, look, this is a well no that's not. This a rectangle isn't it? Ok, it's still a rectangle. It's still a rectangle.

However much I turn it, it's still a rectangle. Yeah, ok?

Diagram of rectangle drawn on paper and then the paper twisted and turned as a demonstration that orientation doesn't alter the shape.

The teacher sketched a rectangle on paper in order to illustrate the concept that orientation does not affect the nature of the shape. This sketch was done on paper at the time mainly because it was quicker than constructing the shape on Cabri. The teacher's return to the paper-and-pencil environment is important because it makes a connection between the two environments: although dynamic variation makes it easier to appreciate that orientation does not affect the shape, the concept still holds in a paper-and-pencil environment. The return to paper-and-pencil is thus an attempt by the teacher to "build connections with the official mathematics outside the microworld", a responsibility which Guin and Trouche (1999) identify as being a crucial part of the teacher's role.

\section{Discussion}

From the sequence of lessons, three teaching strategies have been distilled that serve to facilitate pupils' instrumental genesis in a DGS context. These strategies are clearly not exhaustive: exploiting anomalies of measurement in Cabri such as rounding errors might be another way to promote mathematical thinking, for example. These strategies are specific to DGS in general and Cabri Geometre. They are also analogous to teaching strategies used in other contexts. Guin and Trouche (1999) suggest that teachers should highlight the constraints and limitations of the software to students: in the case of Derive, the discrete and finite nature of the software. Similarly, a dynamic geometry environment such as Cabri is only a discrete model of Euclidean geometry, despite its continuous appearance. All tools and resources have constraints and limitations. In the case of paper and pencil, a limitation is the static nature of the environment. Thus strategies such as those identified in this paper may apply to any teaching resource. In a sense, the teaching strategies mentioned here essentially highlight general principles of mathematics teaching applied to a specific context, in this case DGS. The resource provides a context for learning but cannot teach. The focus of research needs to shift away from the context, towards teachers and the teaching strategies they may employ in order to aid pupils' instrumental genesis. In this way research on ICT may avoid the criticism that the predominant focus has been on technology rather than education.

\section{References}

Bliss, J., M. Askew and S. Macrae. 1996. Effective Teaching and Learning: scaffolding revisited. Oxford Review of Education, 22 (1), 37-61.

Drijvers, P. and K. Gravemeijer. 2005. Computer algebra as an instrument: examples of algebraic schemes. In The Didactical challenge of Symbolic Calculators: turning a computational device into a mathematical instrument, ed. D. Guin, K. Ruthven and L. Trouche, 163-196. New York: Springer Verlag.

Guin, D. and L. Trouche. 1999. The Complex Process of Converting Tools into Mathematical Instruments: the case of calculators. International Journal of Computers for Mathematics Learning, 3(3), 195-227. 
Jones, K. 2000. Providing a Foundation for Deductive Reasoning: students' interpretations when using dynamic geometry software. Educational Studies in Mathematics, 44 (1\&2), 55-85.

Kvale, S. 1996. Interviews: an Introduction to Qualitative Research Interviewing. Sage Publications.

Lagrange, J-B., M. Artigue, C. Laborde and L. Trouche. 2003. Technology and Mathematics Education: A Multidimensional Study of the Evolution of research and Innovation. In Second International Handbook of Mathematics Education, ed. A.J. Bishop, M.A. Clements, C. Keitel, J. Kilpatrick, F.K.S. Leung, 237-269. Dordrecht: Kluwer Academic Publishers.

Marrades, R. and A. Gutiérrez. 2000. Proofs produced by secondary school students learning geometry in a dynamic computer environment. Educational Studies in Mathematics, 44 (1\&2), 87-125.

Ofsted. 2004. 2004 report: ICT in schools - the impact of government initiatives, Secondary Mathematics London. A report from the Office of Her Majesty's Chief Inspector of Schools http://www.ofsted.gov.uk/assets/3646.pdf 